Research Paper

\title{
Protein Kinase $C$ Involvement in Neuroprotective Effects of Thymol and Carvacrol Against Toxicity Induced by Amyloid- $\beta$ in Rat Hippocampal Neurons
}

\author{
Zahra Azizi $^{1}$ (D), Samira Choopani ${ }^{1}$, Mona Salimi $^{1}$ (D), Nahid Majlessi ${ }^{1}$ (D), Nasser Naghdi ${ }^{*}$ (D) \\ 1. Department of Physiology and Pharmacology, Pasteur Institute of Iran, Tehran, Iran.
}

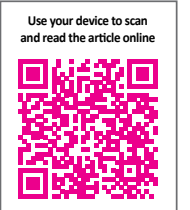

Citation Azizi, Z., Choopani, S., Salimi, M., Majlessi, N.,\& Naghdi, N. (2022). Protein Kinase C Involvement in Neuroprotective Effects of Thymol and Carvacrol Against Toxicity Induced by Amyloid- $\beta$ in Rat Hippocampal Neurons. Basic and Clinical Neuroscience, 13(3), 295-304. http://dx.doi.org/10.32598/bcn.2021.666.2

http://dx.doi.org/10.32598/bcn.2021.666.2

Article info:

Received: 12 Dec 2020

First Revision: 03 Jan 2021

Accepted: 25 Feb 2021

Available Online: 01 May 2022

Keywords:

Thymol, Carvacrol, Protein kinase C, Amyloid $\beta$,

Alzheimer disease

\begin{abstract}
AB S T RACT
Introduction: We have reported that thymol and carvacrol can improve cognitive abilities in Alzheimer Disease (AD) rat models. However, the mechanism of their action is not yet fully understood. Recently, our in vitro results suggested that PC12 cell death induced by A $\beta_{25-35}$ can be protected by thymol and carvacrol via Protein Kinase C (PKC) and Reactive Oxygen Species (ROS) pathways. So, we hypothesize that the mechanisms of thymol and carvacrol in improving the learning impairment in the $\mathrm{AD}$ rat model may be related to their effects on PKC. So, the activity of PKC and protein expression levels of PKC $\alpha$ were examined in the hippocampal cells of the $\mathrm{AD}$ rat model.

Methods: To examine the thymol and carvacrol effects, we performed a behavioral test in $\mathrm{AD}$ rat models induced by $\mathrm{A} \beta_{25-35}$ neurotoxicity. To access the underlying mechanism of the protective effects, western blotting was performed with antibodies against PKC $\alpha$. We also measured the PKC activity assay by Elisa. Histopathological studies were carried out in the hippocampus with Hematoxylin and Eosin (H\&E) staining.

Results: The escape latency increased in A $\beta$-received rats compared to the control group, and thymol and carvacrol reversed this deficit. Furthermore, these compounds could enhance the PKC activity and increase the PKC $\alpha$ expression ratio. Moreover, $\mathrm{H} \& \mathrm{E}$ staining showed that $\mathrm{A} \beta$ caused shrinkage of the CA1 pyramidal neurons. However, thymol and carvacrol treatments could prevent this effect of $\mathrm{A} \beta$ peptides.

Conclusion: This study suggests that Amyloid-Beta $(A \beta)$ results in memory decline and histochemical disturbances in the hippocampus. Moreover, these results revealed that thymol and carvacrol could have protective effects on cognition in AD-like models via PKC activation.
\end{abstract}

\footnotetext{
* Corresponding Author: Nasser Naghdi, PhD.

Address: Department of Physiology and Pharmacology, Pasteur Institute of Iran, Tehran, Iran.

Tel: +98(21) 64112264

E-mail:naghdi@pasteurac.ir
} 


\section{Highlights}

- Rat's ability to find the invisible platform in the Morris Water Maze (MWM) was impaired by Amyloid-Beta (A $\beta$ ) infusion in the hippocampus, while this effect was reversed by thymol or carvacrol administration.

- $\mathrm{A} \beta$ significantly downregulated the Protein Kinase C (PKC) activity in rats' hippocampus.

- Western blot analysis demonstrated that $\mathrm{A} \beta$ significantly reduced $\mathrm{PKC} \alpha$ protein expression in $\mathrm{AD}$ rat model hippocampal cells.

- The expression ratio of PKC $\alpha$ was upregulated following the injection of thymol and carvacrol in rats.

- Injection of $A \beta$ in the hippocampus resulted in histochemical disturbances in CA1 pyramidal neurons.

- Carvacrol and thymol can prevent several histological changes induced by A $\beta$.

\section{Plain Language Summary}

Alzheimer's disease is one of the most important brain diseases in which the learning and memory are impaired. One of the main causes of Alzheimer's disease is the presence of amyloid beta plaques in the neurons. Protein kinase C enzyme reduces amyloid production and accumulation in the brain. In the present study, we tested the possible effects of carvacrol and thymol in a rat model of Alzheimer's disease. Memory impairment was induced in adult rats by intracerebral infusion of amyloid $\beta$. One week later, the memory-impaired animals were treated with carvacrol and thymol. Finally, we tested their memory in a Morris water maze apparatus. Furthermore, their hippocampus was dissected and PKC activity and the neuronal injury was evaluated. Our findings exhibited that thymol and carvacrol improved rats' memory performance. In addition, thymol and carvacrol significantly increased PKC activity and prevented neuronal cell loss in the rat hippocampus. This study shows that thymol and carvacrol have beneficial effects on memory and cognitive function via PKC activation.

\section{Introduction}

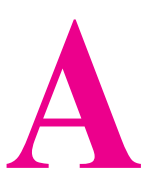

lzheimer Disease (AD), one of the most common causes of dementia, leads to progressive neurodegeneration that affects cognition (Duyckaerts, Delatour, \& Potier, 2009). Neuropathologic characteristics of $\mathrm{AD}$ include Amyloid $\beta(\mathrm{A} \beta)$ accumulation outside the neuronal cells, and neurofibrillary tangle formation inside the cells in multiple brain regions, mainly the hippocampus and the cortical temporal lobe (Duyckaerts et al., 2009). AD causes progressive shrinkage of brain tissues and neuronal death. In the early stages, $\mathrm{AD}$ degenerates hippocampal cells leading to short-term memory loss, followed by diminishing the ability to perform routine tasks. AD progression causes nerve cell injury associated with synaptic loss, leading to gradual deteriorating behavioral changes (Reitz, Brayne, $\&$ Mayeux, 2011).

Recent reports suggest several signaling pathways regulate pathophysiological processes involved in $\mathrm{AD}$ de- velopment and progress. One of these pathways includes Protein Kinase C (PKC), a central kinase in intracellular signal transduction (Crews \& Masliah, 2010; LuckeWold et al., 2015). PKC is recognized as a "memory kinase," and several studies have shown its crucial role in memory function in normal and pathological experimental conditions, including AD models (Lucke-Wold et al., 2015). Additionally, it has been reported that $A \beta$ cytotoxicity could be protected by PKC activation (Han et al., 2004). Twelve PKC isozymes have been identified in molecular studies that are classified into three subgroups: classical, novel, and atypical. Different isoforms of PKC play important roles in many cognitive performances such as learning and memory $(\mathrm{Li}$, et al., 2013; Nelson, Verma, Wender, \& Alkon, 2009; Nelson \& Alkon, 2009).

It has been demonstrated that PKC $\alpha$ and $\mathrm{PKC} \varepsilon$ signaling pathways have a close correlation in neuropathological injuries in $A D$ and $A \beta$ production, and related dementia in transgenic mouse $\mathrm{AD}$ model could be ameliorated by activating these isoforms. Researchers have suggest- 
ed enhancing A $\beta$ degradation and APP $\alpha$-processing pathways as the mechanism of this action (Choi et al., 2006; Li, et al., 2013; Nelson \& Alkon, 2009; Sarajärvi et al., 2018). Meanwhile, the promotion of $\alpha$-secretasemediated APP processing and suppression of A $\beta$ production by PKC $\alpha$ has also been reported (Kinouchi et al., 1995). These studies show that the activation of PKC $\alpha$ has a significant protective effect in many pathological states, such as brain ischemia, neurodegeneration, and aging.

Recent studies have examined the efficacy of many medicinal plants and their active constituents in alleviating $\mathrm{AD}$ symptoms or affecting disease processes in various AD cellular and animal models, as well as clinical trials with patients. These studies have indicated that several species show in vitro and in vivo activities, including antioxidant, anti-inflammatory, anti-cholinesterase, neuroprotective, and even anti-amyloid and cognition-improving effects (Wang, Liu, Li, \& Yang ,2016; Bastianetto \& Quirion, 2004; Kim MH, Kim SH, \& Yang, 2014; Majlessi, Choopani, Kamalinejad, \& Azizi et al., 2012).

Two main constituents in many aromatic plants' essential oils such as Thymus, Zataria, and Origanum species are thymol (2-isopropyl-5-methylphenol) and carvacrol (5-isopropyl-2-methylphenol) (Baser, 2008). These monoterpenic phenols possess some pharmacologic activities, including antioxidant (Azizi, Salimi, Amanzadeh, Majlessi, \& Naghdi, 2020), anti-inflammatory (Basch, Ulbricht, Hammerness, Bevins, \& Sollars, 2004), and AChEI (Jukic, Politeo, Maksimovic, Milos, $\&$ Milos, 2007) effects that appear to help manage AD cognitive deficits.

Our previous research showed that treatment with thymol and carvacrol could protect against many alterations resulting from the administration of $A \beta$ and scopolamine in two AD rat models (Azizi, Ebrahimi, Saadatfar, Kamalinejad, \& Majlessi, 2012). Later, our in vitro results suggested that thymol and carvacrol can protect against PC12 cell death induced by $\mathrm{A} \beta_{25-35}$ via PKC and ROS mitochondrial pathways (Azizi et al., 2020). Considering the PKC hypothesis in the pathological process of AD (Lucke-Wold et al., 2015), we are interested in developing thymol and carvacrol as potential agents for $\mathrm{AD}$ treatment. In this study, we investigated the mechanism of protective effects of thymol and carvacrol in $\mathrm{AD}$ models using $\mathrm{A} \beta$.

\section{Materials and Methods}

\section{Chemicals and agents preparation}

Rabbit polyclonal anti-PKC $\alpha$ (sc-208) and goat antirabbit immunoglobulin $\mathrm{G}$ (IgG) horseradish peroxidase (HRP) (sc-2004) antibodies were purchased from Santa Cruz Biotechnology (Santa Cruz, California, USA). Mouse anti- $\beta$-actin monoclonal antibody was obtained from Cell Signaling Technology (Beverly, MA, USA). Amyloid $\beta$-protein fragment 25-35, thymol, and carvacrol were all provided by Sigma-Aldrich Chemical Company (St. Louis, Missouri, USA). Tween 80 was provided by Merck (Darmstadt, Germany). The protease inhibitor was obtained from Roche (Mannheim, Germany). PKCkinase activity kit and Bryostatin-1 were purchased from Enzo Life Sciences Company (Farmingdale, NY, USA) and Tocris Bioscience (Bristol, UK), respectively.

\section{Animal surgery and Morris Water Maze}

Male albino Wistar rats (200-250 g) were provided by the Pasteur Institute of Iran. Animals were used according to the National Institute of Health Guide for the Care and Use of Laboratory Animals. Experiment procedures were performed in accordance with laboratory animal care and use guidelines of the Pasteur Institute of Iran animal experiment administration committee. We made maximum efforts to minimize the number of animals used and their suffering.

Infusion of $A \beta_{25-35}$ into the rats' hippocampus was performed as in the previous study (Majlessi et al., 2012). Seven days after surgery, spatial reference memory was evaluated using the Morris Water Maze Test (MWM). The water maze and experimental procedure were explained previously (Majlessi, Choopani, Bozorgmehr \& Azizi, 2008). In brief, rats received four trials over five days. During the first 4 days, the platform was hidden and placed in the southwest quadrant center to examine spatial learning. The position of the platform was stable for 4 days, and the acquisition of this task was investigated. On the fifth day, the platform was situated in the southeast quadrant center and was elevated above the water. Each rat swimming path in each trial was recorded automatically using a computerized system, and several parameters were computed and analyzed, such as the escape latency and swimming speed.

Groups ( $\mathrm{n}=10)$ received $0.2 \mathrm{nM}$ bryostatin-1, $0.5,1$, or 2 $\mathrm{mg} / \mathrm{kg}$ thymol, carvacrol, or $2 \mathrm{~mL} / \mathrm{kg} 0.1 \% \mathrm{v} / \mathrm{v}$ Tween 80 (vehicle). All drugs were injected intraperitoneally $30 \mathrm{~min}$ 
before the MWM test each day. One A $\beta$-received group was tested in MWM with no injection (Azizi et al., 2012).

Kinase activity assay

After removing the brains and immediate dissection of hippocampi on a cold plate, they were weighed and quickly homogenized in ice-cold normal saline. Then, the homogenate was centrifuged at $3000 \mathrm{r} / \mathrm{min}$ for 10 $\min$ at $4^{\circ} \mathrm{C}$. The supernatants were separated and stored at $4^{\circ} \mathrm{C}$ for PKC activity assay, according to the manufacturer's instruction for the enzyme-linked immunosorbent assay kit (ENZO, ADI-EKS-420A). The kit was based on a solid-phase ELISA that uses a polyclonal antibody to recognize the phosphorylated form of the substrate. This assay was designed for PKC activity analyses in the solution phase. Optical density was measured at 450 $\mathrm{nm}$ with a Bio-Rad microtiter plate reader. Results are indicated as a percentage of control values.

\section{Western blotting analysis}

Individual rat's hippocampus was homogenized and suspended in $500 \mu \mathrm{L}$ lysis buffer containing $2.5 \mathrm{~mL} 1 \mathrm{M}$ Tris-HCl (pH 7.4), $1500 \mu \mathrm{L} \mathrm{5M} \mathrm{NaCl,} 250$ mg sodium deoxycholate, $1 \%$ SDS $50 \mathrm{~mL}$ plus freshly added protease inhibitor. The suspension was centrifuged at 12000 RPM for $10 \mathrm{~min}$ at $4^{\circ} \mathrm{C}$. Tissue lysates were briefly sonicated, and the supernatant protein content was determined using the Bradford assay. Then, by adding the homogenization buffer, tissue lysates were adjusted to 1 $\mathrm{mg}$ protein $/ \mathrm{mL}$, divided into aliquots, frozen, and stored at $-70^{\circ} \mathrm{C}$ for subsequent western blotting. For western blot, equal amounts of protein were heated to $95^{\circ} \mathrm{C}$, separated in $8 \%$ SDS-poly acrylamide gels, and transferred to PVDF membranes. Next, the membrane was blocked for $2 \mathrm{~h}$ in TBST (50 mmol/L Tris-Cl, $\mathrm{pH} 7.6$, $150 \mathrm{mmol} / \mathrm{L} \mathrm{NaCl}$ and $0.1 \%$ Tween 20 ) containing $1 \%$ $(\mathrm{w} / \mathrm{v})$ casein, and then incubated with primary antibodies (rabbit polyclonal anti-PKC $\varepsilon$ (1:1000), rabbit polyclonal anti-PKC $\alpha$ (1:500), and b-actin (1:1000) overnight. Afterward, they were incubated with Horseradish Peroxidase (HRP)-conjugated goat anti-rabbit IgG for $2 \mathrm{~h}$. Then, the blots were developed by ECL advanced western blotting detection kit, as described. Chemiluminescence detection was linear at 30 to $60 \mathrm{~s}$ of the exposure for all antibodies. The exposed films were scanned, and densitometric analysis was done with ImageJ software. All tests were performed 3 to 5 times with similar results, and the data were analyzed using ANOVA. The control expression level was designated as value "1", and the treatment expression ratios were expressed compared to the control.

\section{Tissue preparation and histological staining}

After the behavioral experiment, animals were anesthetized with $100 \mathrm{mg} / \mathrm{kg}$ sodium pentobarbital and perfused transcardially with $0.9 \%$ saline and then $4 \%$ paraformaldehyde in buffered saline. The rats were decapitated, and their brain tissues were immediately fixed in $4 \%$ paraformaldehyde for 2 to 3 days. The brain tissues were washed under slow-running tap water overnight. Then, the dehydration process was done in ascending grades of ethanol $(70 \%, 80 \%, 90 \%$, absolute alcohol) for 45 min in each change. Next, brain tissues were cleared for $4 \mathrm{~h}$ in two changes of xylene. Afterward, paraffin was impregnated in an oven, and the paraffin blocks were prepared. The blocks were cut using a rotary microtome (Leica RM 2245 ${ }^{\mathrm{TM}}$ ), and a 4- $\mu \mathrm{m}$ paraffin section was obtained. The sections were mounted on grease-free albumenized slides, air dried, and fixed using a slide drier for better fixation of the section. Finally, the tissue sections were stained with hematoxylin and eosin, according to the standard method (Bancroft, , Layton, 2019). Photography was performed at $\times 100$ and $\times 400$ magnifications under the microscope (Leica DM 2500, Germany). Five microscopic fields were randomly chosen for observations in each rat.

\section{Statistical analyses}

Data were shown as Means \pm SEM and analyzed with 1-way ANOVA followed by Tukey's honestly significant difference. $\mathrm{P}<0.05$ was considered significant compared to the $\mathrm{A} \beta_{25-35}$ treatment or the control group.

\section{Results}

Thymol and Carvacrol improving effect on $\mathbf{A} \boldsymbol{\beta}_{25-35}$ induced cognitive impairment

Escape latency was significantly different between $A \beta$ and the control groups $(\mathrm{P}<0.01)$, showing cognitive impairment caused by $A \beta$ administration into the rat hippocampus. However, in animals that received thymol and carvacrol, this deficit was significantly attenuated. As shown in Figure 1, escape latencies during the four days with the hidden platform were significantly different among the tested groups. Post-hoc analysis indicated that $A \beta_{25-35}$ significantly increased escape latency $(\mathrm{P}<0.01)$ compared to the control group. Thymol and carvacrol at doses of $0.5,1$, or $2 \mathrm{mg} / \mathrm{kg}$ reduced $\mathrm{A} \beta_{25-35}$ effects (Figure 1). 


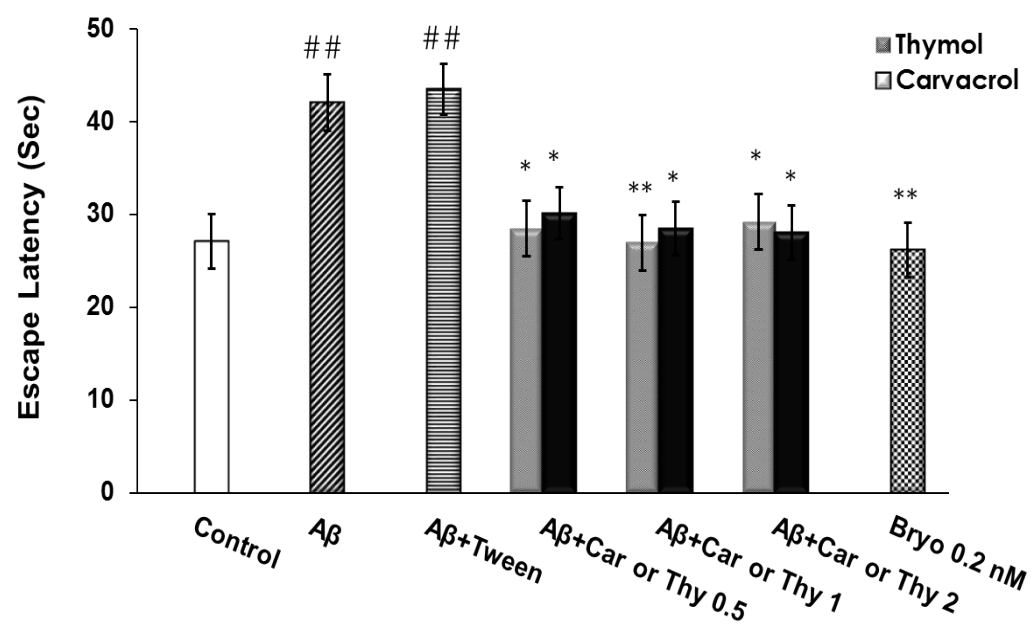

NEUR:SCIENCE

Figure 1. Mean Escape Latencies in Seconds in Each Group yo Locate the Platform in the Morris Water Maze

The latency time in $\mathrm{A} \beta$-received rats was significantly greater than the control group (\#\#P<0.01), while it was significantly shorter in the thymol and carvacrol groups than the $A \beta$ group $\left({ }^{*} \mathrm{P}<0.05\right.$, $\left.{ }^{*} \mathrm{P}<0.01\right)$. Ten groups were tested $(\mathrm{n}=10)$ : control, $\mathrm{A} \beta, \mathrm{A} \beta+$ Tween, $\mathrm{A} \beta+0.5$ $\mathrm{mg} / \mathrm{kg}$ Thy, $\mathrm{A} \beta+1 \mathrm{mg} / \mathrm{kg}$ Thy, $\mathrm{A} \beta+2 \mathrm{mg} / \mathrm{kg}$ Thy, $\mathrm{A} \beta+0.5 \mathrm{mg} / \mathrm{kg}$ Car, $\mathrm{A} \beta+1 \mathrm{mg} / \mathrm{kg}$ Car, $\mathrm{A} \beta+2 \mathrm{mg} / \mathrm{kg}$ Car. Error bars indicate $\pm S E M$.

Car: carvacrol; Thy: thymol.

Effect of Thymol and Carvacrol on PKC activity in hippocampal neurons

Enzyme activity was determined using an assay kit (Enzo Life Science, USA). Protein samples extracted from the hippocampus of the $A \beta$ group considerably inhibited PKC activity compared to the control. Treatment with thymol and carvacrol at concentrations of 0.5 ,
1 , and $2 \mathrm{mg} / \mathrm{kg}$ could also significantly induce the PKC activity (Figure 2).

Thymol and Carvacrol increased the expression of PKCa

To determine the mechanism of the thymol and carvacrol effect, the protein expression of PKC $\alpha$ was accessed with western blotting in the hippocampus. In the $A \beta+$

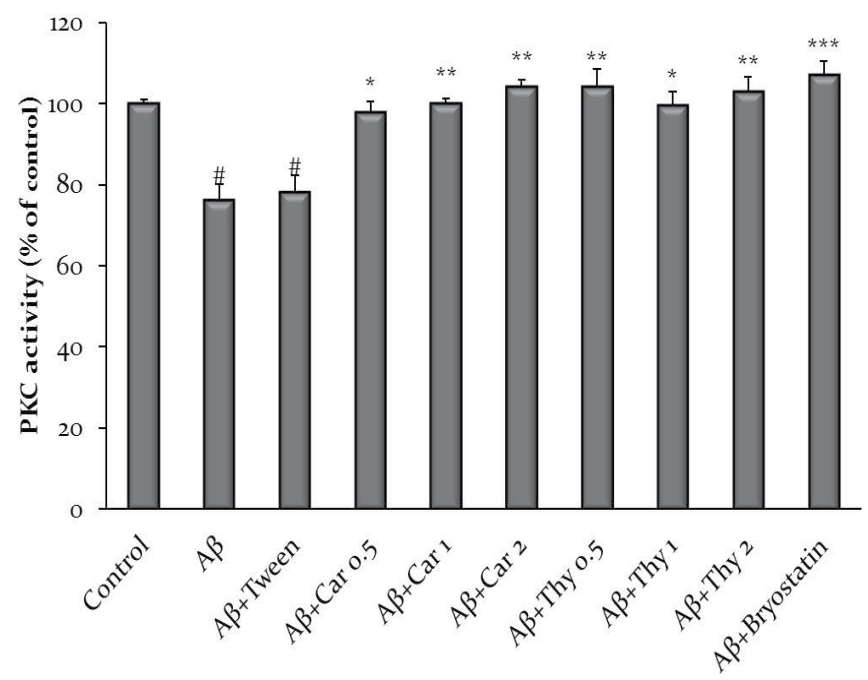

NEUR SCIENCE

Figure 2. Thymol and Carvacrol Effect on Protein Kinase C (PKC) activity inhibited by amyloid beta (A $\beta$ )

The PKC activity was significantly lower in $\mathrm{A} \beta$ samples compare to the control group ( $(\mathrm{P}<0.05)$. While compared to $\mathrm{A} \beta$, the $\mathrm{PKC}$ activity was significantly higher in the carvacrol (a), thymol (b) $(1 \mathrm{mg} / \mathrm{kg}$ and $2 \mathrm{mg} / \mathrm{kg})$ and bryostatin $(0.2 \mathrm{nM})$ groups. The data were shown as Mean \pm SEM. ${ }^{*} \mathrm{P}<0.05$ vs. control, ${ }^{*} \mathrm{P}<0.05,{ }^{* *} \mathrm{P}<0.01$, ${ }^{* * *} \mathrm{P}<0.001$ vs $\mathrm{A} \beta$. Experiments were performed in triplicate.

Car: carvacrol; Thy: thymol. 

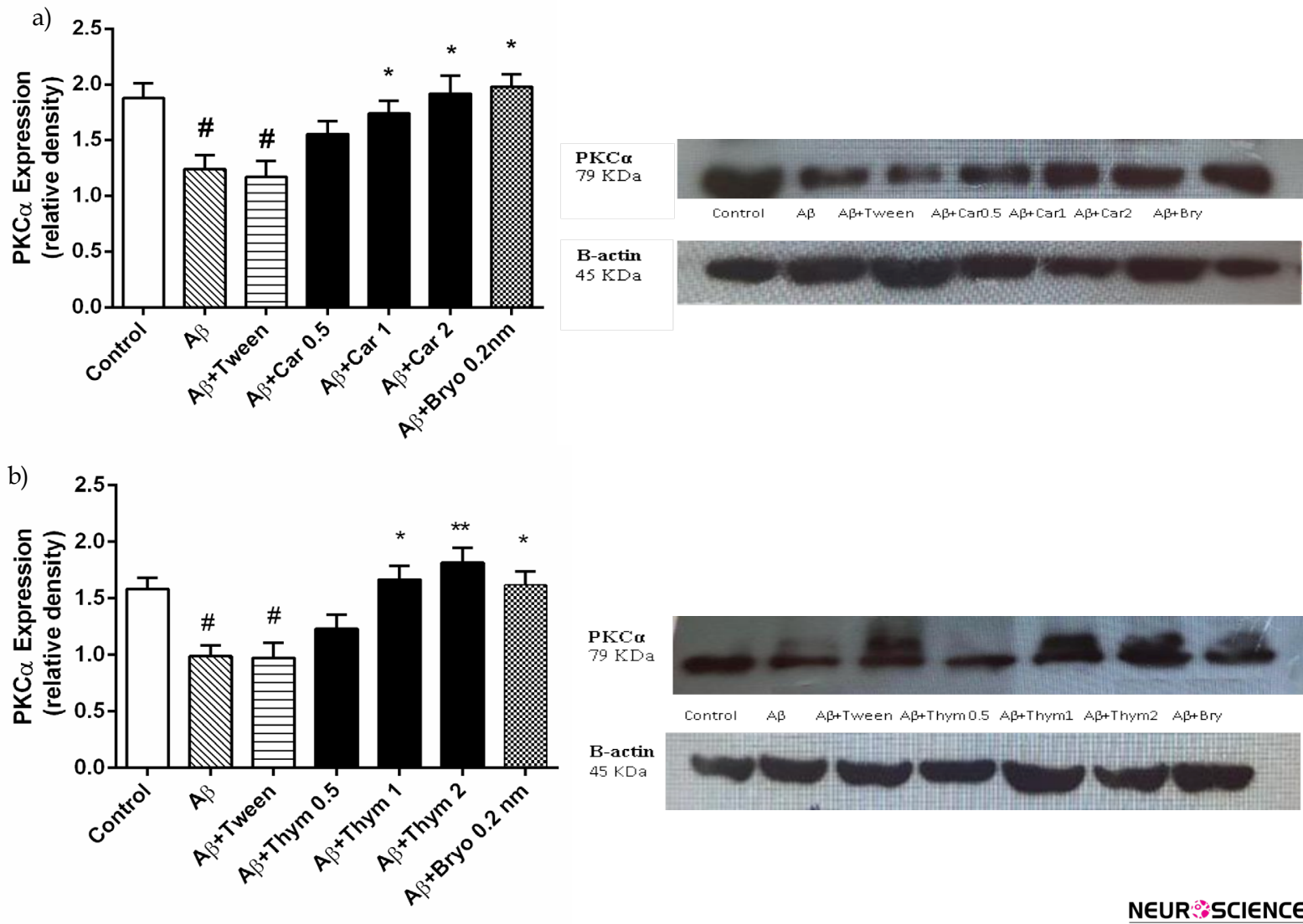

Figure 3. The Effect of Carvacrol (a) and Thymol (b) on Protein Kinase C (PKC)a Expression in Rat Hippocampus

Representative Western blots of levels of PKCa expression were detected with rabbit polyclonal anti-PKCa (sc-208). This Figure shows the western blot of PKCa and the quantification with densitometry. There was a significant reduction of PKCa expression in the A $\beta$ group compared to the control group $\left({ }^{*} \mathrm{P}<0.05\right)$. While compared to the $\mathrm{A} \beta$ group, $\mathrm{PKC}$ expression was significantly higher in carvacrol (a), thymol (b) $(1 \mathrm{mg} / \mathrm{kg}$ and $2 \mathrm{mg} / \mathrm{kg})$ and Bryostatin $(0.2 \mathrm{nM})$ groups $\left({ }^{*} \mathrm{P}<0.05\right)$. Densitometric analysis is expressed after normalizing the levels of $\beta$-actin. Data are presented as the Mean \pm SEM. Experiments were carried out in triplicate. ${ }^{*} \mathrm{P}<0.05$ vs control, ${ }^{*} \mathrm{P}<0.05$, ${ }^{* *} \mathrm{P}<0.01$ vs $\mathrm{A} \beta$.

thymol, carvacrol, or bryostatin group, $\mathrm{PKC} \alpha$ expression was significantly higher than in the $\mathrm{A} \beta$ group $(\mathrm{P}<0.01$, Figure 3 parts a and $\mathrm{b})$. Therefore, thymol and carvacrol upregulated PKC $\alpha$ expression in the brain and can exert their neuroprotective effects by activating PKC.

\section{Protective effect of thymol and carvacrol on hip- pocampal neurons injury}

The cell nuclei became blue-black by hematoxylin, shows intranuclear details clearly, while cell cytoplasm and connective tissue fibers show pink, orange, and red shades by eosin (Bancroft, , Layton, 2019). The neuropathological damage was evaluated by irregular neuronal shape, arrangement, and death. Irregular neuronal shape, arrangement, and hippocampal neuronal death were observed following $A \beta$ administration. This injury was dramatically reduced by thymol, carvacrol, and bryostatin. Also, the number of survived neurons was significantly higher than the $A \beta$ group. This finding sug- gests that thymol and carvacrol can prevent $A \beta$-induced neuronal damage.

\section{Discussion}

Our previous research suggested thymol and carvacrol potentials to protect $\mathrm{PC} 12$ cells against toxicity induced by $\mathrm{A} \beta_{25-35}$. Our results indicate that these compounds may induce neuroprotective action via increased PKC activity (Azizi et al., 2020). We also demonstrated the neuroprotective effects of thymol and carvacrol in AD animal models (Azizi et al., 2012). Our present results indicate that thymol and carvacrol significantly enhance PKC activity. Further, these compounds increase the PKC $\alpha$ expression ratio. In addition, the results of $H \& E$ staining show the protective effects of thymol and carvacrol on hippocampal cells. As a result, dysfunction and death of hippocampal neurons induced by $\mathrm{A} \beta$ could be protected by thymol and carvacrol, and consequent learning and memory deficits could be prevented. We 
a)

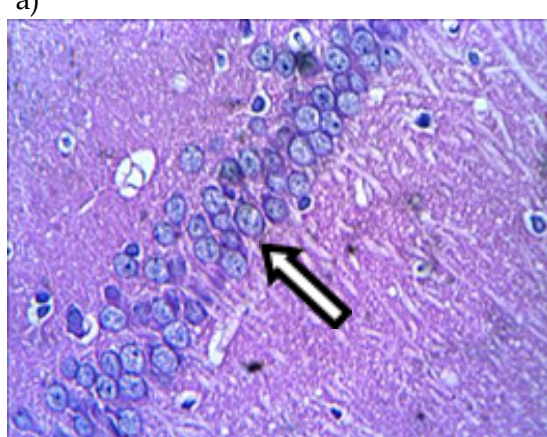

c)

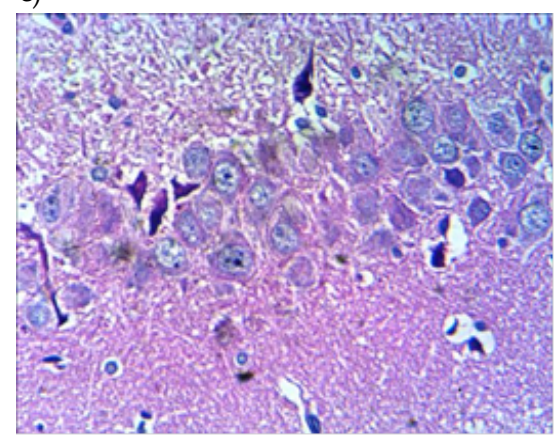

e)

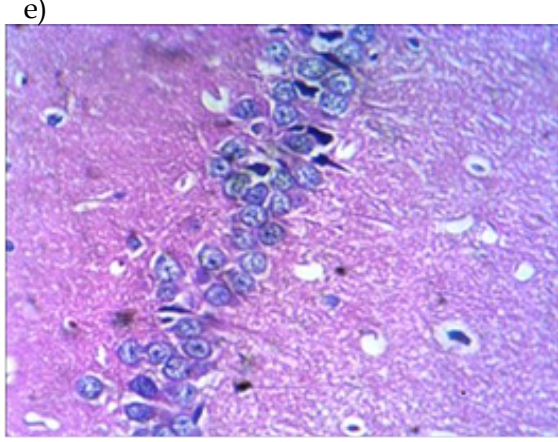

b)

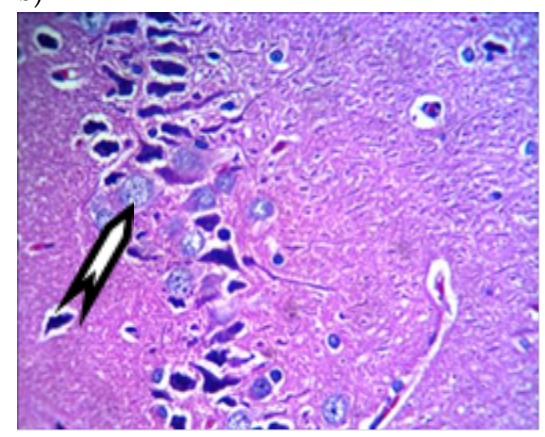

d)

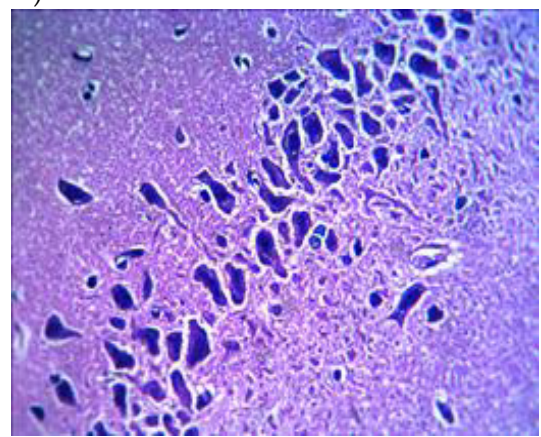

f)

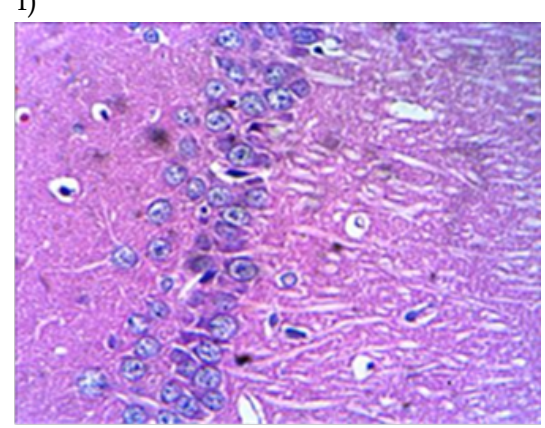

NEUR SCIENCE

Figure 4. Neuroprotective Activity of Thymol and Carvacrol on Morphological Changes and Neuronal Injury of Rat Hippocampus Caused by $\mathrm{A} \beta$ Neurotoxicity

H\&E staining of mice hippocampal CA1 slices presents a) the control group neurons show normal shape and size; they are regularly arranged with a nucleus-colored blue marked with an arrow. The neuronal count was less in b) $A \beta$-treated and c) $A \beta+T$ ween 80 compared to the control; d) Car and e) Thy groups show size increase in nerve cell bodies compared to $A \beta$ treated group. A mixed pattern of normal and shrinkage neurons was observed; f) in the bryostatin group, neurons have almost normal morphology, and their arrangement was regular and few condensed neuronal cells (Representative of at least three experiments).

Car: carvacrol; Thy: thymol. Normal cells are marked with $\Uparrow$. Shrinkage cells are marked with $\widehat{W}$.

confirmed that thymol and carvacrol treatment improved $\mathrm{A} \beta_{25-35}$-induced cognitive impairment in rats' hippocampus through increasing PKC activity.

Recently, it has been indicated that the neuropharmacological properties of phytochemicals derived from medicinal plants may be clinically beneficial in $\mathrm{AD}$ (Dey, Bhattacharya, Mukherjee, \& Pandey, 2017). So, an increasing number of herbal extracts and active plant constituents have been investigated for their protective effects on AD in recent years (Kalász et al., 2018; Wang, et al.,2016). Thymol and carvacrol, natural monoterpenoid phenols, are obtained from many plants belonging to the Lamiaceae family and have shown in vivo or in vitro activities, including antioxidant, neuroprotective, and memory enhancement (Sharifi-Rad, 2018; Salehi, 2018). The neuroprotective effects of these compounds have been reported in a variety of animal models, including AD (Azizi et al., 2012; Asadbegi, Yaghmaei, Salehi, Komaki, \& Ebrahim-Habibi, 2017; Guan et al., 2019) and Parkinson disease (Manouchehrabadi, Farhadi, Azizi, \& Torkaman-Boutorabi, 2020). One recent study has 
demonstrated significant attenuation of harmful effects of $A \beta_{25-35}$ injection on the escape latency and traveled distance. Also, improving $A \beta$ induced by thymol suggested the neuroprotective properties of this compound (Asadbegi et al., 2017). Another recent in vivo study has shown that carvacrol could ameliorate brain $\mathrm{AD}$ induced by $\mathrm{AlCl}_{3}$, and attributed this effect to the anti-inflammatory and antioxidant activities of carvacrol (Medhat et al., 2019). These results indicate that carvacrol attenuates memory impairments through inhibiting hippocampal neuronal injury inhibition. Another study showed improvements in bradykinesia, motor coordination, locomotor activity, and a reduction in apomorphine-induced rotation by carvacrol in 6-OHDA-stimulated rats. These findings suggested that carvacrol exerts neuroprotective effects in Parkinson disease models (Manouchehrabadi, 2020). In the present study, we evaluated thymol and carvacrol effects on $A \beta$-induced cognitive deficits in an $\mathrm{AD}$ rodent model. $\mathrm{A} \beta$ infusion in the rat's hippocampus CA1 region was shown to significantly impair the rat's performance in finding the invisible platform in the MWM. Moreover, this deficiency was reversed by thymol or carvacrol administration. Accordingly, our findings provided evidence for thymol and carvacrol efficacy in enhancing cognitive performance.

More recently, researchers have demonstrated that PKC activation might affect the pathophysiology of AD and attenuate related cognitive deficits (Schrott et al., 2015; Etcheberrigaray et al., 2004; Amiri et al., 2020). It has been shown that bryostatin-1 reduces amyloid accumulation in $\mathrm{AD}$ transgenic mice brains (Hongpaisan, Miao-Kun Sun, \& Alkon, 2011). Our previous results indicate that thymol and carvacrol can cause PKC activation like bryostatin-1 (Azizi et al., 2020). Consistent with these data, our findings from the PKC activity assay reveal that thymol and carvacrol reversed $A \beta$-induced neurotoxicity and consequently improved behavioral outcomes in $\mathrm{AD}$ model rats. In accordance with our results, Chen et al. displayed that the antioxidant property of carvacrol might lead to its cardioprotective activity through MAPK/ERK signaling pathway activation, as PKC's common downstream effectors. Therefore, considering the possible neuroprotective role of $\mathrm{PKC}$ in $\mathrm{AD}$, it is reasonable to suggest the administration of thymol and carvacrol as potential disease-modifying agents.

PKC $\alpha$ belongs to the serine/threonine kinases family, and its signal transduction is mediated by calcium and diacylglycerol as second messengers (Newton, 2010). It has been demonstrated that the activation of PKC $\alpha$ could elevate $\alpha$-secretase activity that inhibits $A \beta$ production (Murakami et al., 2020). In the present study, we also observed that PKC $\alpha$ expression level is significantly increased in the thymol and carvacrol groups compared to $A \beta$. Following our results, Yabuki, Wu, \& Fukunaga (2019) have displayed that ST101, as a PKC $\alpha$ activator, improved schizophrenic symptoms and memory deficits in rats through $\mathrm{CaMKII} / \mathrm{PKC} \alpha$ signaling stimulation in hippocampal cells (Yabuki, et al., 2019). Hippocampus in the temporal lobe is considered the main target of $\mathrm{AD}$ pathophysiology (Bondolfi et al., 2002; Li et al., 2013). So, histochemical alterations were assessed in the hippocampal neurons of the rat model of $A D$, developed by injection of $A \beta_{25-35}$. H\&E staining showed shrinkage in the CA1 pyramidal neurons and neuronal loss in the rat model of AD. Furthermore, daily treatment with thymol and carvacrol effectively prevented several histological disturbances induced by $A \beta$ injection into $C A 1$. In the present study, decreased hippocampal volume due to neuronal shrinkage and loss through accelerated apoptosis in $\mathrm{AD}$ is detectable using imaging and pathological studies. Shrinkage and neuronal loss have been reported in the rat models of AD (Bondolfi et al., 2002; 2002; Li et al., 2013). and in clinical studies (Simić, Kostović, Winblad, \& Bogdanović, 1997; Zarow et al., 2005). In vitro studies have indicated that hippocampal neuronal cells can be protected against toxicity induced by $A \beta$ through PKC pharmacologic activation.

Our study suggests that thymol and carvacrol improved learning and memory deficit by stimulating hippocampal PKC signaling in $\mathrm{AD}$ model rat brains. Because the stimulation of PKC activity might potentially enhance cognitive function and perhaps modulate the pathophysiology of AD, our findings offer a bright horizon for new drug design and development.

In conclusion, our study demonstrates that thymol and carvacrol stimulated the PKC pathway in AD model rats. Considering the PKC activating capacity of thymol and carvacrol, these terpenoid compounds could be suggested as therapeutic agents for AD management. It warrants further study and holds promise for AD patients.

\section{Ethical Considerations}

\section{Compliance with ethical guidelines}

Principles of the Helsinki Declaration Code of Ethics Convention were observed. 


\section{Funding}

The Graduate Department of the Pasteur Institute of Iran supported the study. The research is a $\mathrm{PhD}$ dissertation of the first author.

\section{Authors' contributions}

Conceptualization and Supervision: Nasser Naghdi; Investigation, Methodology, Writing-original draft: Zahra Azizi; Data collection: Samira Choopani; Data analysis, Writing-review \& editing: Mona Salimi and Nahid Majlessi.

\section{Conflict of interest}

The authors declared no conflict of interest.

\section{References}

Alkon, D. L., Sun, M. K., \& Nelson, T.J. (2007). PKC signaling deficits: A mechanistic hypothesis for the origins of Alzheimer's disease. Trends in Pharmacological Sciences, 28(2), 51-60. [DOI:10.1016/j.tips.2006.12.002] [PMID]

Amiri, S., Azadmanesh, K., Dehghan Shasaltaneh, M., Mayahi, V., \& Naghdi, N. (2020). The Implication of androgens in the presence of protein kinase $\mathrm{C}$ to repair Alzheimer's diseaseinduced cognitive dysfunction. Iranian Biomedical Journal, 24(2), 64-80. [DOI:10.29252/ibj.24.2.64] [PMID] [PMCID]

Asadbegi, M., Yaghmaei, P., Salehi, I., Komaki, A., \& EbrahimHabibi, A. (2017). Investigation of thymol effect on learning and memory impairment induced by intrahippocampal injection of amyloid beta peptide in high fat diet- fed rats. Metabolic Brain Disease, 32(3), 827-839. [DOI:10.1007/s11011-0179960-0] [PMID]

Azizi, Z., Ebrahimi, S. H., Saadatfar, E., Kamalinejad, M., \& Majlessi, N. (2012). Cognitive-enhancing activity of thymol and carvacrol in two rat models of dementia. Behavioral Pharmacology, 23(3), 241-249. [DOI:10.1097/FBP.0b013e3283534301] [PMID]

Azizi, Z., Salimi, M., Amanzadeh, A., Majelssi, N., \& Naghdi, N. (2020). Carvacrol and thymol attenuate cytotoxicity induced by amyloid $\beta 25-35$ via activating protein kinase $\mathrm{c}$ and inhibiting oxidative stress in PC12 cells. Iranian Biomedical Journal, 24(4), 243-50. [DOI:10.29252/ibj.24.4.243] [PMID] [PMCID]

Basch, E., Ulbricht, C., Hammerness, P., Bevins, A., \& Sollars, D. (2004). Thyme (Thymus vulgaris L.), thymol. Journal of Herbal Pharmacotherapy, 4(1), 49-67. [PMID]

Baser, K. H. C. (2008). Biological and pharmacological activities of carvacrol and carvacrol bearing essential oils. Current Pharmaceutical Design, 14(29), 3106-3119. [DOI:10.2174/13816120 8786404227] [PMID]

Bastianetto, S., \& Quirion, R. (2004). Natural antioxidants and neurodegenerative diseases. Frontiers in Bioscience, 9, 3447-52. [DOI:10.2741/1493] [PMID]
Bondolfi, L., Calhoun, M., Ermini, F., Kuhn, H. G., Wiederhold, K. H., \& Walker, L., et al. (2002). Amyloid-associated neuron loss and gliogenesis in the neocortex of amyloid precursor protein transgenic mice. Journal of Neuroscience, 22(2), 515-522. [DOI:10.1523/JNEUROSCI.22-02-00515.2002] [PMID] [PMCID]

Choi, D. S., Wang, D., Yu, G. Q., Zhu, G., Kharazia, V. N., \& Paredes, J. P., et al. (2006). PKC epsilon increases endothelin converting enzyme activity and reduces amyloid plaque pathology in transgenic mice. Proceedings of the National Academy of Sciences of the United States of America, 103(21), 8215-8220. [DOI:10.1073/pnas.0509725103] [PMID] [PMCID]

Crews, L., \& Masliah, E. (2010). Molecular mechanisms of neurodegeneration in Alzheimer's disease. Human Molecular Genetics, 19(R1), R12-R20. [DOI:10.1093/hmg/ddq160] [PMID] [PMCID]

Dey, A., Bhattacharya, R., Mukherjee, A., \& Pandey, D. K. (2017). Natural products against Alzheimer's disease: Pharmaco-therapeutics and biotechnological interventions. Biotechnology Advances, 35(2), 178-216. [DOI:10.1016/j.biotechadv.2016.12.005] [PMID]

Duyckaerts, C., Delatour, B., \& Potier, M, C. (2009). Classification and basic pathology of Alzheimer's disease. Acta Neuropathologica, 118(1), 5-36. [DOI:10.1007/s00401-009-0532-1] [PMID]

Etcheberrigaray, R., Tan, M., Dewachter, I., Kuipéri C., Van der Auwera, I., \& Wera, S., et al. (2004). Therapeutic effects of PKC activators in Alzheimer's disease transgenic mice. Proceedings of the National Academy of Sciences of the United States of America, 101(30), 11141-11146. [DOI:10.1073/ pnas.0403921101] [PMID] [PMCID]

Guan, X., Li, X., Yang, X., Yan, J., Shi, P., \& Ba, L., et al. (2019). The neuroprotective effects of carvacrol on ischemia/reperfusion-induced hippocampal neuronal impairment by ferroptosis mitigation. Life Sciences, 235:116795. [DOI:10.1016/j. lfs.2019.116795] [PMID]

Han, Y. S., Zheng, W. H., Bastianetto, S., Chabot, J. G., \& Quirion, R. (2004). Neuroprotective effects of resveratrol against beta-amyloid-induced neurotoxicity in rat hippocampal neurons: Involvement of protein kinase C. British Journal of Pharmacology, 141(6), 997-1005. [DOI:10.1038/sj.bjp.0705688] [PMID] [PMCID]

Hongpaisan, J., Sun, M. K., \& Alkon D. L. (2011). PKC ع activation prevents synaptic loss, $A \beta$ elevation, and cognitive deficits in Alzheimer's disease transgenic mice. Journal of Neuroscience, 31(2), 630-643. [DOI:10.1523/JNEUROSCI.5209-10.2011] [PMID] [PMCID]

Jukic, M., Politeo, O., Maksimovic, M., Milos, M. \& Milos, M. (2007). In vitro acetylcholinesterase inhibitory properties of thymol, carvacrol and their derivatives thymoquinone and thymohydroquinone. Phytotherapy Research, 21(3), 259-61. [DOI:10.1002/ptr.2063] [PMID]

Kalász, H., Ojha, S., Tekes, K., Szőke, É., Mohanraj, R., \& Fahim M., et al. (2018). Pharmacognostical sources of popular medicine to treat Alzheimer's disease. The Open Medicinal Chemistry Journal, 12, 23-35. [DOI:10.2174/1874104501812010023] [PMID] [PMCID]

Kim, M. H., Kim, S. H., \& Yang, W. M. (2014). Mechanisms of action of phytochemicals from medicinal herbs in the treat ment of Alzheimer's disease. Planta Medica, 80(15), 1249-1258. [DOI:10.1055/s-0034-1383038] [PMID] 
Kinouchi, T., Sorimach, H., Maruyama, K., Mizuno, K., Ohno, S., \& Ishiura, S., et al. (1995). Conventional protein kinase $\mathrm{C}$ (PKC)- $\alpha$ and novel PKC $\varepsilon$, but not $-\delta$, increase the secretion of an N-terminal fragment of Alzheimer's disease amyloid precursor protein from PKC cDNA transfected 3Y1 fibroblasts. FEBS Letters. 364(2), 203-206. [DOI:10.1016/00145793(95)00392-M]

Li, X., Zheng, L., Zhang, J., Zhou, X., Ma, C., \& Chen, Y., et al. (2013). Differences in functional brain activation and hippocampal volume among amnestic mild cognitive impairment subtypes. Current Alzheimer Research, 10(10), 10801089. [DOI: $10.2174 / 15672050113106660172]$ [PMID]

Lucke-Wold, B. P., Turner, R. C., Logsdon, A. F., Simpkins, J. W., Alkon, D. L., \& Smith K. E., et al. (2015). Common mechanisms of Alzheimer's disease and ischemic stroke: The role of protein kinase $\mathrm{C}$ in the progression of age-related neurodegeneration. Journal of Alzheimer's Disease, 43(3), 711-724. [DOI:10.3233/JAD-141422] [PMID] [PMCID]

Majlessi, N., Choopani, S., Bozorgmehr, T., \& Azizi, Z. (2008). Involvement of hippocampal nitric oxide in spatial learning in the rat. Neurobiology of Learning and Memory, 90(2):413-419. [DOI:10.1016/j.nlm.2008.04.010] [PMID]

Manouchehrabadi, M., Farhadi, M., Azizi, Z., \& Torkaman-Boutorabi, A. (2020). Carvacrol protects against 6-Hydroxydopamine-induced neurotoxicity in in vivo and in vitro models of Parkinson's disease. Neurotoxicity Research, 37(1),156-170. [DOI:10.1007/s12640-019-00088-w] [PMID]

Medhat, D., El-Mezayen, H. A., El-Naggar, M. E., Farrag, A. R., Abdelgawad, M. E., Hussein, J., et al. (2019). Evaluation of urinary 8-hydroxy-2-deoxyguanosine level in experimental Alzheimer's disease: Impact of carvacrol nanoparticles. Molecular Biology Reports, 46(4), 4517-4527. [DOI:10.1007/s11033-01904907-3] [PMID]

Murakami, K., Yoshimura, M., Nakagawa, S., Kume, T., Kondo, T., \& Inoue, H, et al. (2020). Evaluation of toxic Amyloid 42 oligomers in rat primary cerebral cortex cells and human iPSderived neurons treated with 10-Me-Aplog-1, a new PKC activator. International Journal of Molecular Sciences, 21(4), 1179 [DOI:10.3390/ijms21041179] [PMID] [PMCID]

Nelson, T. J., \& Alkon, D. L. (2009). Neuroprotective versus tumorigenic protein kinase $\mathrm{C}$ activators. Trends in Biochemical Sciences, 34(3), 136-145. [DOI:10.1016/j.tibs.2008.11.006] [PMID]

Newton, A. C. (2010). Protein kinase C: Poised to signal. American Journal of Physiology: Endocrinology and Metabolism, 298(3) E395-E402. [DOI:10.1152/ajpendo.00477.2009] [PMID] [PMCID]

Reitz, C., Brayne, C., \& Mayeux, R. (2011). Epidemiology of Alzheimer disease. Nature Reviews Neurology, 7(3), 137-152. [DOI:10.1038/nrneurol.2011.2] [PMID] [PMCID]

Salehi, B., Mishra, A. P., Shukla, I., Sharifi-Rad, M., Contreras, M. D. M., \& Segura-Carretero A., et al. (2018). Thymol, thyme, and other plant sources: Health and potential uses. Phytotherapy Research, 32(9), 1688-1706. [DOI:10.1002/ptr.6109] [PMID]

Sarajärvi, T., Jäntti, M., Paldanius, K. M. A., Natunen, T., Wu, J. C., \& Mäkinen, P., et al. (2018). Protein kinase C -activating isophthalate derivatives mitigate Alzheimer's disease-related cellular alterations. Neuropharmacology, 141, 76-88. [DOI:10.1016/j. neuropharm.2018.08.020] [PMID]
Schrott, L. M., Jackson, K., Yi, P., Dietz, F., Johnson, G. S., \& Basting T. F., et al. (2015). Acute oral Bryostatin-1 administration improves learning deficits in the APP/PS1 transgenic mouse model of Alzheimer's disease. Current Alzheimer Research, 12(1), 22-31. [DOI:10.2174/1567205012666141218141904] [PMID]

Sharifi-Rad, M., Varoni, E. M., Iriti, M., Martorell, M., Setzer, W. N., \& Del Mar Contreras, M., et al. (2018). Carvacrol and human health: A comprehensive review. Phytotherapy Research, 32(9), 1675-1687. [DOI:10.1002/ptr.6103] [PMID]

Bancroft, J. D., Layton, C. (2019). The hematoxylins and eosin. In: S. K. Suvarna, C. Layton, J. D. Bancroft, (Eds.), Bancroft's Theory and Practice of Histological Techniques (pp. 126-138). Amsterdam: Elsevier. [DOI:10.1016/B978-0-7020-6864-5.00010-4]

Wang, Z.Y., Liu, J. G., Li, H., Yang, H. M. (2016). Pharmacological effects of active components of Chinese herbal medicine in the treatment of Alzheimer's disease: A Review. American Journal of Chinese Medicine, 44(8), 1525-1541. [DOI:10.1142/ S0192415X16500853] [PMID]

Yabuki, Y., Wu, L., \& Fukunaga, K. (2019). Cognitive enhancer ST101 improves schizophrenia-like behaviors in neonatal ventral hippocampus-lesioned rats in association with improved CaMKII/PKC pathway. Journal of Pharmacological Sciences, 140(3), 263-272. [DOI:10.1016/j.jphs.2019.07.015] [PMID] 